\title{
Association between axillary lymph node involvement and clinicopathological features of breast cancer among Indonesian women
}

\author{
Dody Novrial, ${ }^{1}$ Gita Nawangtantrini, ${ }^{1}$ Hidayat Sulistyo, ${ }^{1}$ Henida Dwi Sari, ${ }^{2}$ Wahyu Djatmiko ${ }^{3}$
}

Check for updates

pISSN: 0853-1773 • elSSN: 2252-8083 https://doi.org/10.13181/mji.oa.193306 Med J Indones. 2020;29:32-7

Received: November 20, 2018 Accepted: September 2, 2019

Authors' affiliations:

${ }^{1}$ Department of Anatomical Pathology, Faculty of Medicine, Universitas Jenderal Soedirman, Margono Soekarjo Hospital, Purwokerto, Indonesia, ${ }^{2}$ Faculty of Medicine, Universitas Jenderal Soedirman, Purwokerto, Indonesia, ${ }^{3}$ Department of Internal Medicine, Faculty of Medicine, Universitas Jenderal Soedirman, Margono Soekarjo Hospital, Purwokerto, Indonesia

\section{Corresponding author:}

Dody Novrial

Department of Anatomical Pathology, Faculty of Medicine, Universitas

Jenderal Soedirman, Margono Soekarjo Hospital, Jalan Dr. Gumbreg No. 1, East Purwokerto, Banyumas, Central Java 53112, Indonesia

Tel/Fax: +62-81-622022/+62-81-624990

E-mail: dodynovrial@unsoed.ac.id

\begin{abstract}
BACKGROUND Some clinicopathological features play roles in the spread of breast cancer to axillary lymph node (ALN). However, their roles as predictive factors are not well-established. This study was conducted to determine the correlation between the clinicopathological features of breast cancer and the risk of ALN involvement in Indonesian women.
\end{abstract}

METHODS This cross-sectional study was conducted in Margono Soekarjo Hospital using archival data from January 2017 to June 2018. All subjects with breast cancer who had undergone modified radical mastectomies without any evidence of distant metastasis were included. Chi-square and Fisher's exact tests were performed to assess the relationship between ALN involvement and age, menopausal status, laterality, tumor size, tumor stage, histological type, tumor grade, lymphovascular space invasion (LVSI), skin or nipple infiltration, perineural invasion, estrogen receptor, progesterone receptor, and human epidermal growth factor receptor 2 status. The odds ratio of each variable was evaluated using ordinal regression analysis.

RESULTS Stage 3 breast cancer had the worst status of ALN involvement compared with stage $1(\mathrm{OR}=3.49 ; 95 \% \mathrm{Cl}=1.51-8.08)$ and stage $2(\mathrm{OR}=3.04 ; 95 \% \mathrm{Cl}=1.32-6.98)$. Likewise, positive LVSI also had the worst status of ALN involvement compared with negative LVSI $(\mathrm{OR}=8.68 ; 95 \% \mathrm{Cl}=4.23-17.81)$.

CONCLUSIONS Tumor stage and LVSI could be considered as independent predictive factors of ALN involvement in patients with breast cancer, especially among Indonesian women.

KEYWORDS breast cancer, lymph node metastases, lymphovascular space invasion, tumor stage
Breast cancer is the most common malignancy and the leading cause of cancer deaths among female. ${ }^{1}$ There were 2.1 million new cases of female breast cancers in 2018 worldwide, accounting for almost 1 in 4 cancer cases among women. ${ }^{2}$ In Indonesia, the incidence of breast cancer was approximately 40 per 1,000 with high mortality rate. ${ }^{3,4}$ Hence, it is important to understand the clinical and pathological features that influence the prognostic factors of breast cancer.
The development of metastases is the most important poor prognostic outcome in all cancers. In breast cancer, axillary lymph node (ALN) involvement becomes a crucial step before metastases. ${ }^{5}$ It is used for predicting the prognosis of breast cancer in the absence of distant metastases. Breast cancer patient with ALN involvement have a poorer prognosis. ${ }^{6}$ However, up to $30 \%$ of patients with ALN-negative breast cancer have a low disease-free survival in 5 and 10 
years after their initial diagnosis. ${ }^{6}$ This study was aimed to investigate breast cancer with ALN involvement among Indonesian women, and its correlation with several clinicopathological features. There might be considerable variation in its presentation according to the region.

\section{METHODS}

This study was conducted at Margono Soekarjo Hospital Purwokerto and was approved by the Ethics Committee of the Faculty of Medicine, Universitas Jenderal Soedirman (No: 2978/UN23.07.5.1/PN.1/2018). We reviewed the details of pathologically diagnosed patients with breast cancer recorded from January 2017 to June 2018. A total of 107 from 177 patients with breast cancer were included consecutively in this cross-sectional study. Only patients with invasive breast cancer who underwent modified mastectomies, followed by ALN resection (level I, II, or III), with no evidence of distant metastases were included in this study. Patients who had received radiation to the affected side of breast or the axilla or had undergone neoadjuvant chemotherapy were excluded. Clinicopathological profiles of patients with breast cancer, including age, menopausal status, laterality, tumor size, tumor stage, histological type, tumor grade, lymphovascular space invasion (LVSI), skin or nipple infiltration, perineural invasion, hormonal status, and human epidermal growth factor receptor 2 (HER2) expression were analyzed.

The $8^{\text {th }}$ edition of the breast cancer staging system from the American Joint Committee on Cancer was used to assess the tumor. ${ }^{7}$ Breast cancer cases were classified based on tumor size (T1: $<2 \mathrm{~cm}, \mathrm{~T}_{2}: 2-5 \mathrm{~cm}$, T3: $>5 \mathrm{~cm}$, and T4: any size with evidence of chest wall or skin infiltration) and nodal status (No: negative ALN involvement, N1: 1-3 ALN involvement, N2: 4-9 ALN involvement, and N3: $\geq 10$ ALN involvement). Staging was classified according to the TNM staging system? and histological grading of the tumor was based on the modified Scarff-Bloom-Richardson. ${ }^{8}$ Histological data included LVSI, perineural invasion, and skin or nipple infiltration. Immunohistochemical analyses were conducted to determine the estrogen receptor (ER), progesterone receptor (PR), and HER2 status of breast cancer. The ER and PR were interpreted as positive when $>1 \%$ of tumor cells demonstrated positive nuclear staining. ${ }^{9}$ Score of $3^{+}$(strong complete membrane staining in $>10 \%$ of tumor cells) was considered as HER2 positive. ${ }^{10}$

Bivariate analysis was performed using chi-square or Fisher's exact probability test to determine the associations between variables. The complementary log-log link function was used in the multivariate ordinal regression analysis with ALN involvement as an outcome variable, and the significant clinicopathological presentations in bivariate analysis as independent variables. Odds ratios (ORs) were calculated to assess the relative risk of having ALN involvement, and the nature of palindromic invariance was used to facilitate interpretation. ${ }^{11} \mathrm{~A} p$-value $<0.05$ was considered significant.

\section{RESULTS}

Table 1 shows the clinicopathological features of patients with breast cancer. The mean (standard deviation) age of the patients was 52.7 (10.12) years, and most of them were $>40$ year-old age. More than half of the patients were postmenopausal women. Right-sided breast cancers were diagnosed in most of the patients. Majority of breast cancer patients had a grade tumor size of $\mathrm{T} 2$, and most of them were in stage I with grade 2 invasive ductal type carcinoma. Hormonal status and HER2 expression were positive in more than half of the patients.

In the bivariate analysis, premenopausal women, left-sided breast cancer, larger tumor size, advanced tumor stage, and positive LVSI were significant risks for ALN involvement. Table 2 shows the results of the multivariate analysis with ALN involvement as dependent variable. We found that tumor stage and LVSI had a significant influence on ALN involvement. Using palindromic invariance properties, we discovered that patients with stage 3 breast cancer tended to have the worst status of ALN involvement compared with stage $1(\mathrm{OR}=3.49 ; 95 \% \mathrm{Cl}=1.51-8.08)$ and stage 2 $(O R=3.04 ; 95 \% \mathrm{Cl}=1.32-6.98)$. Meanwhile, breast cancer patients with positive LVSI also tended to have ALN involvement compared with negative LVSI $(\mathrm{OR}=8.68 ; 95 \% \mathrm{Cl}=4.23-17.81)$.

\section{DISCUSSION}

ALN status is an important predictor for breast cancer prognosis. Several previous institutional studies have demonstrated the role of positive ALN 
Table 1. Associations between clinicopathological features and ALN involvement

\begin{tabular}{|c|c|c|c|c|c|}
\hline \multirow{2}{*}{ Features } & \multicolumn{4}{|c|}{ ALN involvement, $\mathrm{n}(\%)$} & \multirow{2}{*}{$p^{*}$} \\
\hline & NO & N1 & N2 & N3 & \\
\hline Age (years) & & & & & $0.294^{+}$ \\
\hline$\leq 40$ & $3(5.2)$ & $2(6.3)$ & $3(18.8)$ & $1(100.0)$ & \\
\hline$>40$ & $55(94.8)$ & $30(93.7)$ & $13(81.2)$ & $0(0.0)$ & \\
\hline Menopausal status & & & & & 0.005 \\
\hline Premenopause & $15(25.9)$ & $16(50.0)$ & $8(50.0)$ & $1(100.0)$ & \\
\hline Postmenopause & $43(74.1)$ & $16(50.0)$ & $8(50.0)$ & $0(0.0)$ & \\
\hline Laterality & & & & & 0.007 \\
\hline Right breast & $39(67.2)$ & $14(43.7)$ & $7(43.8)$ & $0(0.0)$ & \\
\hline Left breast & $19(32.8)$ & $18(56.3)$ & $9(56.2)$ & $1(100.0)$ & \\
\hline Tumor size & & & & & 0.040 \\
\hline $\mathrm{T} 1$ & $9(15.5)$ & $5(15.6)$ & $0(0.0)$ & $0(0.0)$ & \\
\hline $\mathrm{T} 2$ & $34(58.6)$ & $17(53.1)$ & $5(31.3)$ & $0(0.0)$ & \\
\hline T3 & $10(17.2)$ & 7 (21.9) & $10(62.5)$ & $0(0.0)$ & \\
\hline T4 & $5(8.7)$ & $3(9.4)$ & $1(6.2)$ & $1(100.0)$ & \\
\hline Tumor stage & & & & & $<0.001$ \\
\hline 1 & $32(55.2)$ & $13(40.6)$ & $2(12.5)$ & $0(0.0)$ & \\
\hline II & $19(32.8)$ & $11(34.4)$ & $1(6.3)$ & $0(0.0)$ & \\
\hline III & $7(12.0)$ & $8(25.0)$ & $13(81.2)$ & $1(100.0)$ & \\
\hline Histological type & & & & & $1.000^{+}$ \\
\hline Invasive ductal & $53(91.4)$ & $32(100.0)$ & $12(75.0)$ & $1(100.0)$ & \\
\hline Invasive lobular & $5(8.6)$ & $0(0.0)$ & $4(25.0)$ & $0(0.0)$ & \\
\hline Tumor grade & & & & & 0.546 \\
\hline Grade 1 & $0(0.0)$ & $0(0.0)$ & $0(0.0)$ & $0(0.0)$ & \\
\hline Grade 2 & $37(63.8)$ & $21(65.6)$ & $11(68.8)$ & $1(100.0)$ & \\
\hline Grade 3 & $21(36.2)$ & $11(34.4)$ & $5(31.2)$ & $0(0.0)$ & \\
\hline LVSI & & & & & $<0.001$ \\
\hline Negative & $51(87.9)$ & $5(15.6)$ & $0(0.0)$ & $0(0.0)$ & \\
\hline Positive & $7(12.1)$ & $27(84.4)$ & $16(100.0)$ & $1(100.0)$ & \\
\hline Skin or nipple infiltration & & & & & 0.367 \\
\hline Negative & $53(91.4)$ & $27(84.4)$ & $15(93.8)$ & $0(0.0)$ & \\
\hline Positive & $5(8.6)$ & $5(15.6)$ & $1(6.2)$ & $1(100.0)$ & \\
\hline Perineural invasion & & & & & 0.128 \\
\hline Negative & $39(67.2)$ & $27(84.4)$ & $12(75.0)$ & $1(100.0)$ & \\
\hline Positive & $19(32.8)$ & $5(15.6)$ & $4(25.0)$ & $0(0.0)$ & \\
\hline Estrogen receptor & & & & & 1.000 \\
\hline Negative & $24(41.4)$ & $11(34.4)$ & $9(56.3)$ & $1(100.0)$ & \\
\hline Positive & $34(58.6)$ & $21(65.6)$ & $7(43.7)$ & $0(0.0)$ & \\
\hline Progesterone receptor & & & & & 0.700 \\
\hline Negative & $27(46.6)$ & $14(43.8)$ & $9(56.3)$ & $1(100.0)$ & \\
\hline Positive & $31(53.4)$ & $18(56.2)$ & $7(43.7)$ & $0(0.0)$ & \\
\hline HER2 receptor & & & & & 0.844 \\
\hline Negative & $22(37.9)$ & 15 (46.9) & $6(37.5)$ & $0(0.0)$ & \\
\hline Positive & $36(62.1)$ & 17 (53.1) & $10(62.5)$ & $1(100.0)$ & \\
\hline
\end{tabular}

ALN=axillary lymph node; LVSI=lymphovascular space invasion; HER2=human epidermal growth factor receptor 2

${ }^{*} p$-value was analyzed using chi-square by combining N1-N3 as positive ALN involvement and No as negative ALN involvement; ${ }^{\dagger}$ Fisher's exact test 
involvement in developing distant metastases and breast cancer recurrences. ${ }^{12-14}$ However, there were differences in these study results, which might be due to differences in demographics and research methods. In this study, ALN involvement among Indonesian breast cancer patients and its correlation with several clinicopathological variables were evaluated.

Our results revealed the relationship between ALN involvement and several clinicopathological features of breast cancer patients such as menopausal status, laterality, tumor size, tumor stage, and LVSI. These findings were consistent with a similar study in Pakistan, except for laterality. ${ }^{14}$ Another study in Brazil also reported a relationship between tumor size, LVSI, and ALN involvement. ${ }^{15}$ Meanwhile, a study in China demonstrated that tumor size was one of three independent predictive factors of sentinel lymph node metastases in early breast cancer, other than age and tumor grade. ${ }^{16}$ In contrast, other studies in the USA ${ }^{17}$ and Sudan ${ }^{18}$ reported that tumor size was not related to ALN involvement as well as tumor grade, age, $E R, P R$, and HER2 status. It is likely due to the small sample of their studies as much as 64 and 81 samples, respectively.

Studies have described menopausal status as one of predictive factors of ALN involvement. ${ }^{14,19}$ This study reported ALN involvement in premenopausal patients with breast cancer was higher than in postmenopausal patients. There was a similar study showed premenopausal patients in breast cancer were more likely to have an advanced stage of tumor, higher histological grade, larger tumor size, and ALN involvement. ${ }^{20}$

Several studies have consistently documented that unilateral breast cancer in women is more frequent in the left breast than in the right breast. A large cohort study conducted in the UK reported an incidence ratio (left to right) of 1.07 for breast cancer. ${ }^{21}$ Amer reported that breast cancer was detected predominantly on the left side with a left to right ratio of 1.1 in all age groups, except for patients aged 50-59, $<30$, and $>90$ years. ${ }^{22}$ Interestingly, we found a higher incidence of right-sided breast cancer (56.1\%) than left-sided breast cancer in this study. This difference might be due to the most of our subjects (62.6\%) were older women (aged $>50$ years), and $43.9 \%$ of them were aged 50-59 years. The heterogeneous nature of breast cancer might also play a role in this result as reported by Melnik et $\mathrm{al}^{23}$ that patients born in the Middle East or Asian countries had a predominance of right-sided tumors, whereas those born elsewhere had a left-sided predominance.
Table 2. Odds ratio for clinicopathological predictors of ALN involvement

\begin{tabular}{lllll}
\hline Features & Coeff & OR & $95 \% \mathrm{Cl}$ & $p^{*}$ \\
\hline Menopausal status & & & & 0.170 \\
\hline Premenopause & -0.361 & 0.69 & $0.416-1.166$ & \\
\hline Postmenopause & & 1.00 & & 0.332 \\
\hline Laterality & & & & \\
\hline Right breast & -0.247 & 0.78 & $0.474-1.287$ & \\
\hline Left breast & & 1.00 & & 0.205 \\
\hline Tumor size & & & & 0.776 \\
\hline T1 & 0.797 & 2.21 & $0.647-7.606$ & 0.299 \\
\hline T2 & 0.151 & 1.16 & $0.410-3.300$ & \\
\hline T3 & 0.513 & 1.67 & $0.634-4.393$ & \\
\hline T4 & & 1.00 & & 0.003 \\
\hline Tumor stage & & & & 0.009 \\
\hline I & -1.252 & 0.28 & $0.124-0.661$ & \\
\hline II & -1.112 & 0.32 & $0.143-0.756$ & $<0.001$ \\
\hline III & & 1.00 & & \\
\hline LVSI & & & & \\
\hline Negative & -2.162 & 0.11 & $0.056-0.236$ & \\
\hline Positive & & 1.00 & & \\
\hline
\end{tabular}

ALN=axillary lymph node; $\mathrm{OR}=$ odds ratio; $\mathrm{Cl}=$ confidence interval; $\mathrm{LVSI}=$ lymphovascular space invasion ${ }^{*} p$-value was analyzed using multivariate ordinal regression analysis 
The possible explanation for our finding is the breastfeeding pattern. Most of the population is righthanded, and most of the nursing mothers would use their left arm to hold the baby while feeding, and therefore the left breast is more often used for lactation than the right one. This finding is similar to that of a previous study in the Chinese Tanka population. In that study, the women had a tradition of wearing clothes with the opening part on the right side, and hence, they feed their baby only with the right breast. It was observed that among Tanka's postmenopausal women who had breastfed unilaterally, the risk of developing breast cancer was significantly higher in the contra lateral (unsucked) breast. ${ }^{24}$ Furthermore, it has been consistently documented that lactation is a protective factor for breast cancer. ${ }^{25}$ The protection offered by breastfeeding could persists in postmenopausal women even after age 50 year since the first lactation. ${ }^{26}$ However, we did not collect data about the patient's history of breastfeeding in this study, and therefore further research is necessary to confirm this hypothesis.

In this study, patients with left-sided breast cancer had a higher rate of ALN involvement than those with right-sided breast cancer. Excess of being left-sided over right sided breast cancer remains a controversy. In an investigational study about the effect of cancer laterality in five major paired organs, the authors stated that there was no significant difference in breast cancer. ${ }^{14}$ On the other hand, a study on 4,215 patients with breast cancer demonstrated that left laterality is an independent prognostic factor of metastases in patients with breast cancer in $\mathrm{N}_{3}$ stage. It was associated with a shorter time to first metastases, an increase in the risk for distant metastases, and axial bone involvement. ${ }^{5}$

Most of studies on breast cancer have reported larger tumor size as a risk factor for ALN involvement. Patients with breast cancer with tumor size $>2 \mathrm{~cm}$ are associated with advanced stage, higher risk for nodal metastases, and poor prognosis. ${ }^{14,27,28}$ Although there was a relationship between menopausal status, laterality, and tumor size with ALN involvement of patients with breast cancer in this study, however, they could not be used as predictive factors based on the multivariate analysis.

In this study, tumor stage and LVSI were found to be the two clinicopathological variables that showed significant results in both bivariate and multivariate analyses. A higher stage of tumor tends to have a worse ALN status. This finding agrees with the literature, suggesting that more advanced staging has a worse prognosis for breast cancer. ${ }^{29,30} \mathrm{~A}$ similar result from a study in Pakistan also supported our finding. The researchers reported that the highest risk of nodal metastases was seen in stage IV patients with breast cancer. ${ }^{14}$

LVSI is determined based on the presence of tumor emboli within definite endothelial-lined space that could be observed in histological breast cancer slides. Two studies conducted in South Korea reported the relationship between LVSI and poor prognosis of both operable invasive breast cancer and breast cancer treated with neoadjuvant chemotherapy. ${ }^{31,32}$ LVSI as a predictor of node metastases ${ }^{27}$ and prognostic factor of breast cancer ${ }^{31,32}$ also has been reported. Their results were similar with our study that showed $47.7 \%$ of patients with breast cancer had positive LVSI, and $86.3 \%$ of them had ALN involvement. In conclusion, tumor stage and LVSI could be considered as two independent predictive factors of ALN involvement in patients with breast cancer, especially among Indonesian women. However, we acknowledge, as a limitation of this study, that the effect of clinical and pathological variables of breast cancer on ALN involvement needs to be explored in a larger population.

\section{Conflict of interest}

The authors affirm no conflict of interest in this study.

\section{Acknowledgment}

We would like to thank Joko Mulyanto, MD, M.Sc for the knowledge shared and advice for the statistical analysis.

\section{Funding Sources}

This research was supported by the Riset Institusi Grant 2018 from Universitas Jenderal Soedirman.

\section{REFERENCES}

1. Ferlay J, Soerjomataram I, Dikshit R, Eser S, Mathers C, Rebelo $M$, et al. Cancer incidence and mortality worldwide: sources, methods and major patterns in GLOBOCAN 2012. Int J Cancer. 2015;136(5):E359-86.

2. Bray F, Ferlay J, Soerjomataram I, Siegel RL, Torre LA, Jemal A. Global cancer statistics 2018: GLOBOCAN estimates of incidence and mortality worldwide for 36 cancers in 185 countries. CA Cancer J Clin. 2018;68(6):394-424.

3. Ferlay J, Soerjomataram I, Ervik M, Dikshit R, Eser S, Mathers C, et al. GLOBOCAN 2012 estimated cancer incidence, mortality and prevalence worldwide in 2012 v1.0: IARC Cancer Base No. 11 [Internet]. Lyon: International Agency for Research on Cancer; 2013 [cited 2016 Mar 7]. Available from: http://globocan.iarc.fr.

4. Ng CJ, Teo CH, Abdullah N, Tan WP, Tan HM. Relationships between cancer pattern, country income and geographical region in Asia. BMC Cancer. 2015;15:613.

5. Karatas F, Sahin S, Erdem GU, Ates O, Babacan T, Akin S, et al. 
Left laterality is an independent prognostic factor for metastasis in N3 stage breast cancer. J BUON. 2016;21(4):851-8.

6. Nouh MA, Ismail H, El-Din NH, El-Bolkainy MN. Lymph node metastasis in breast carcinoma: clinicopathological correlations in 3747 patients. J Egypt Natl Canc Inst. 2004;16(1):50-6.

7. Gabriel N, James L, Carl J, Stephen B, Elizabeth A, Hope S, et al. Breast. In: Mahul B, editor. American Joint Committee on Cancer (AJCC) cancer staging manual. 8th ed. New York: Springer; 2017. p. 589-628.

8. Tavassoli FA, Devilee P. Pathology and genetics: tumours of the breast and female genital organs. WHO Classification of Tumours series - volume IV. Lyon: IARC Press; 2003. p. 18-9.

9. Hammond ME, Hayes DF, Dowsett M, Allred DC, Hagerty KL, Badve S, et al. American Society of Clinical Oncology/College of American Pathologists Guideline recommendations for immunohistochemical testing of estrogen and progesterone receptors in breast cancer. J Clin Oncol. 2010;28(16):2784-95.

10. Ali EM, Ahmed AR, Ali AM. Correlation of breast cancer subtypes based on ER, PR and HER2 expression with axillary lymph node status. Cancer Oncol Res. 2014;2(4):51-7.

11. Smith TJ, McKenna CM. An examination of ordinal regression goodness-of-fit indices under varied sample conditions and link functions. Multiple Linear Regression Viewpoints. 2012;38(1):17.

12. Lale Atahan I, Yildiz F, Ozyigit G, Sari S, Gurkaynak M, Selek U, et al. Percent positive axillary lymph node metastasis predicts survival in patients with non-metastatic breast cancer. Acta Oncol. 2008;47(2):232-8.

13. Wallgren A, Bonetti M, Gelber RD, Goldhirsch A, CastiglioneGertsch M, Holmberg SB, et al. Risk factors for locoregional recurrence among breast cancer patients: results from International Breast Cancer Study Group Trials I through VII. J Clin Oncol. 2003;21(7):1205-13.

14. Hadi NI, Jamal Q. Comparison of clinicopathological characteristics of lymph node positive and lymph node negative breast cancer. Pak J Med Sci. 2016;32(4):863-8.

15. Oliveira Filho HR, Dória MT, Piato JR, Soares Junior JM, Filassi $J R$, Baracat EC, et al. Criteria for prediction of metastatic axillary lymph nodes in early-stage breast cancer. Rev Bras Ginecol Obstet. 2015;37(7):308-13.

16. Ding J, Jiang L, Wu W. Predictive value of clinicopathological characteristics for sentinel lymph node metastasis in early breast cancer. Med Sci Monit. 2017;23:4102-8.

17. Blackburn HL, Ellsworth DL, Shriver CD, Ellsworth RE. Breast cancer metastasis to the axillary lymph nodes: are changes to the lymph node "soil" localized or systemic? Breast Cancer. 2017:11:1178223417691246.

18. Gismalla M, Elhassan M, Abass M. Clinical and pathological factors predicting axillary nodal metastasis in breast cancer patients of central Sudan: a single institution experience. Saudi J Health Sci. 2019;8(3):146-50.

19. Chandrashekar S, Ajith VL, Ashwin Raghavendra A. Axillary lymph node status, age at presentation and menopausal status in female breast cancer patients attending a government tertiary care teaching hospital in Mysore, Karnataka, India. Int Surg J. 2017;4(5):1566-8.

20. Chollet-Hinton L, Anders CK, Tse CK, Bell MB, Yang YC, Carey $\mathrm{LA}$, et al. Breast cancer biologic and etiologic heterogeneity by young age and menopausal status in the Carolina Breast Cancer Study: a case-control study. Breast Cancer Res. 2016;18(79).

21. Roychoudhuri R, Putcha V, Møller H. Cancer and laterality: a study of the five major paired organs (UK). Cancer Causes Control. 2006;17(5):655-62.

22. Amer MH. Genetic factors and breast cancer laterality. Cancer Manag Res. 2014;6:191-203.

23. Melnik Y, Slater P, Steinitz R, Davies A. Breast cancer in Israel: laterality and survival. J Cancer Res Clin Oncol. 1979;95(3):291-3.

24. Ing R, Petrakis NL, Ho JH. Unilateral breast-feeding and breast cancer. Lancet. 1977;2(8029):124-7.

25. Anstey EH, Shoemaker ML, Barrera CM, O'Neil ME, Verma $A B$, Holman DM. Breastfeeding and breast cancer risk reduction: implications for black mothers. Am J Prev Med. 2017;53(3S1):S40-6.

26. Lee SY, Kim MT, Kim SW, Song MS, Yoon SJ. Effect of lifetime lactation on breast cancer risk: a Korean women's cohort study. Int J Cancer. 2003;105(3):390-3.

27. Moosavi SA, Abdirad A, Omranipour R, Hadji M, Razavi AE, Najafi M. Clinicopathologic features predicting involvement of non-sentinel axillary lymph nodes in Iranian women with breast cancer. Asian Pac J Cancer Prev. 2014;15(17):7049-54.

28. Friedman D, Gipponi M, Murelli F, Meszaros P, Solari N, Massa $M$, et al. Predictive factors of non-sentinel lymph node involvement in patients with invasive breast cancer and sentinel node micrometastases. Anticancer Res. 2013;33(10):4509-14.

29. Dong G, Wang D, Liang X, Gao H, Wang L, Yu X, et al. Factors related to survival rates for breast cancer patients. Int J Clin Exp Med. 2014;7(10):3719-24.

30. Camacho-Rivera M, Ragin C, Roach V, Kalwar T, Taioli E. Breast cancer clinical characteristics and outcomes in Trinidad and Tobago. J Immigrant Minority Health. 2015;17:765-72.

31. Song YJ, Shin SH, Cho JS, Park MH, Yoon JH, Jegal YJ. The role of lymphovascular invasion as a prognostic factor in patients with lymph node-positive operable Invasive breast cancer. J Breast Cancer. 2011;14(3):198-203.

32. Ryu YJ, Kang SJ, Cho JS, Yoon JH, Park MH. Lymphovascular invasion can be better than pathologic complete response to predict prognosis in breast cancer treated with neoadjuvant chemotherapy. Medicine. 2018;97(30):e11647. 